\section{SURGICAL TREATMENT OF HABITUAL CRIMINALS.}

BY A. J. OCHSNER, M.D.

SURGEOX IS CHIEF OF AUGUSTAYA nOSPITAL AND ST, MARY'S HOSPITAY. CHICAQO.

During the past two years I have had an opportu. nity of making observations in two cases which seem to $m e$ to be of especial interest in pointing out a reasonable plan for the surgical treatment of habitual criminals of the male sex.

Case 1.-Mr. G., a merchant, married, 43 years of age, came under my care July 22, 1897, giving the following history Although he had never been very rugged, he had never suffered from any disease except an attack of intermittent fever at the age of 16 . He has always suffered from constipation, and for three months has suffered from a throbbing pain in the region of the prostate gland. More force is required in voiding the urine and evacuating the bowels than formerly, causing a slight protrusion on each side in the vicinity of the inguinal canals.

Present condition: $\mathrm{He}$ is fairly well nourished, although he has lost twenty pounde during the past three months, which makes his present weight ten pounds below his average. The chest is well developed, heart and lungs normal, abdomen slightly scaphoid, slightly tender throughout but not resistant. Rectal examination shows large internal hemorrhoids, and a uniformly enlarged prostate gland which is tender upon pres. sure. The temperature and pulse are normal, the urine has a specific gravity of 1024 , is acid, contains a very slight trace of albumin, but is otherwise normal. There is pain in the epi gastric region, beginning half an hour after meals and con tinuing for two to three hours. Portions of undigested food, especially lettuce, berries and other uncooked fruits, are evacuated with the feces, as well as large masses of mucus. The patient is extremely nervous because he fears the presence of a carcinoma in the rectum. He has received careful internal and local treatment without benefit for several months. The en largement and irritability of the prostate gland has constantly increased.

My treatment consisted in resection of the vasa deferentia on both sides through an incision less than one inch in length, just below the external inguinal ring. The hemorrhoids were also removed by means of clamp and cautery. The irritation in the region of the prostate gland subsided almost entirely before be left the hospital, two weeks after the operation, and his general health improved very rapidly. At the present time, twenty months after the operation, he is perfectly well, and his sexual power, which had been somewhat impaired before the operation, is fully as good as at any time during his life, which shows that in this case there has been no harmful effect in this direction from the resection of the vasa deferentia.

Case 2,-A laborer, married, 54 years of age, whose previous history was good, with the exception of an attack of malaria and one of typhoid fever, came under my care Sept. 27, 1897, euffering from urinary obstruction due to the presence of an enlarged prostate gland the size of half an orange. $\mathrm{He}$ claimed to have had no venereal disease. An attempt at catheterization the previous night had been followed by a chill and severe pain in the region of the prostate gland.

The operation consisted in resection of the vasa deferentia, as in the previous case. The prostate gland became more painful and the swelling increased from day to day. One week after the first operation I opened a large abscess of the gland very freely into the rectum, by means of the Paquelin cautery, and tamponed the abscess cavity with iodoform gauze saturated with compound tincture of benzoin. The wounds over the vasa deferentia had already healed. The wound in the prostate healed in three weeks, and the patient has been perfectly well ever since, and has found no impairment of his sexual desire or power.

It has been demonstrated beyond a doubt that a very large proportion of all criminals, degenerates and perverts have come from parents similarly afflic- ted. It has aiso been shown, especially by Lombroso, that there are certain inherited anatomic defects which characterize criminals, so that there are undoubtedly born criminals. There are a certain num. ber of criminals who have acquired their vice from contact. A fairly normal individual, being placed while young in an environment suitable to derelop criminal tendencies, will be much more likely to develop into a criminal than were he placed under opposite conditions. This fact in itself makes it de. sirable, for the general welfare and safety of the community, to reduce as much as possible the number of children born in the families of criminals because their surroundings must necessarily be favorable to the development of vicious tendencies.

Statistics show (E. Bleuler, Lombroso, etc.) that fully three-fourths of all crimes are committed by habitual criminals. Taking these two facts into consideration it would seem that if it were possible to eliminate all habitual criminals from the possibility of having chil. dren, there would soon be a very marked decrease in this class, and naturally, also a consequent decrease in the number of criminals from contact.

So far as female criminals are concerned, nature usually protects the community against the likelihood of offspring, because a very large proportion of these individuals acquire a specific endometritis and salpingitis usually resulting in an occlusion of the Fallopian tubes early in their career, hence their sterility is assured. Ligation and section of the Fallopian tubes has been suggested.

In order to accomplish this end in male criminals, a method must be employed which will not in itself be a punishment to the criminal. It must not result in a deformity, neither must it endanger his life, nor must it interfere with his enjoyment of life should he reform and become a useful member of society.

Castration has been recommended as a punishment for certain crimes, and has been practiced without legal sanction in many cases. Whenever and whereever this has been advocated, it has met with the strongest possible opposition, because it practically destroys the possibility for the future enjoyment of life. Judging from the results obtained in the two cases reported above, it is evidently possible to obtain the same result, so far as sterility is concerned, without in any way interfering with the criminal's possibilities of future enjoyment of life.

It will be necessary to increase the number of observations, but we have analogic conditions in patients whose vasa deferentia have been totally obstructed as the result of a gonorrheal inflammation. Although these patients are necessarily sterile, there is never any lack of sexual inclination resulting from this condition. I have resected the vasa deferentia in a considerable number of patients suffering from hypertrophied prostates, but they were all older than these two, and all were either impotent or widowers, and could consequently not aid in making competent observations.

The operation which I would suggest consists in the following steps: 1 , thorough disinfection of the surface over the external inguinal ring; 2 , infiltration of the tissues with a solution of one grain each of muriate of morphia, muriate of cocain and sodium chlorid to the ounce of sterilized water: 3 , an incision in the direction and directly over the cord, not to exceed one inch in length, down to the vas deferens; 4, isolating this structure for the distance of half an inch; 5 , liga- 
tion with catgut and section one-quarter of an inch be. low this; 6 , closure of the wound with a buried catgut stitch, and application of a collodion dressing. The entire operation can be performed on both sides in less than ten minutes, without any pain to the patient. The wound will heal so perfectly that no scar can be discovered.

The advantages of dealing with habitual criminals in this manner can be summed up as follows:

1. It would do away with hereditary criminals from the father's side.

2. Aside from being sterile the criminal would remain in his normal condition.

3. This method would protect the community at large without harming the criminal.

4. 'The same treatment could reasonably be suggested for chronic inebriates, imbeciles, perverts and paupers.

710 Sedgwick Street.

\section{RECURRING GONORRHEA.}

\section{BY HARRY GREENBERG, M.D.}

INSTRUCTOR IN GYNECOLOGY, WISCONSIN COLLEGE OF PHYSTCIANS AND SURGEONS. MILWALKEE, WIS.

V. F., single, merchant, aged 26 , consulted me on July 2, 1898 , for an attack of gonorrheal urethritis, and under treatment with potassium permanganate solution irrigations for one month, was discharged cured. He was then instructed to abstain from the use of alcohol in any form, and was warned against marrying for at least one year from date of discharge, as he was then engaged to be married to a refined young woman of this city.

On March 2, 1899, he again consulted me as to the advisability of marrying, and assured me that during all these months, he had noticed no discharge from his urethra, and at no time felt any inconvenience. He also stated - and I think truthfully-that he did not during that time partake of any alcoholic drinks, and had not indulged in sexual intercourse. Physical examination revealed nothing.

He was married one week later, and again consulted me in ten days from the date of his marriage, for a discharge from his urethra and all symptoms of acute gonorrheal urethritis, which diagnosis was substantiated by the microscope. Three days later his wife consulted me for burning urination and vaginal dis. charge, which on examination proved to be of gonorrheal infection, likewise substantiated by the microscope. This young woman I had treated for uterine displacement, and had examined her but two days previous to her marriage, and as $I$ at no time had occasion to doubt her innocence, the infection can be attributed to no other cause than that she contracted it from her husband.

This is but one of many similar cases that have come under my notice, but none, where I could so definitely attribute the recurring infection to an old and apparently cured gonorrhea.

This case is of interest in once more reviving the question: When may our patients, after cessation of the discharge from a gonorrheal urethritis, marry without fear of relapse and infecting the innocent woman? In an article in the Joursal of March 25, under the heading of "Treatment of Gonorrheal Urethritis," the author, after recommending a certain line of treatment, says that after the discharge ceases and micro-

scopic examination reveals no gonococci, the patient may be discharged and, in his own words, relapse is impossible without infection. The case above cited certainly does not warrant this, his positive assertion.

While it is true that many cases of gonorrheal urethritis suffer no relapse, it is also true, in many instances, that although the microscope will fail to show any gonococci in the urethral secretions, yet they exist latent in some of the folds of the urethra, harmless in their present state, but liable to regain their former virulence under favorable conditions, which a temporary congestion of the urethra will afford. Immoderate use of alcohol, and excessive venery-both conditions common in the newly-married -have the effect of producing a hyperemia of the sexual organs, and produce therefore a good nutrient medium for the latent gonococci to thrive on. It may also be possible that the gonococci, while harmless in their present position in the male urethra, after being deposited in the vagina, affording them a fresh soil, will again become virulent and produce a gonorrheal vaginitis, which will in return reinfect the man on a subsequent coition.

This same fact is also applicable in the female, after a gonorrheal vaginitis. I have observed, on examining prostitutes who had at some period been affected with gonorrhea, but were now apparently free from it, that they are nevertheless prone to infect the male uretbra with gonorrhea. I have also carefully investigated several cases where the man has contracted the infection from a woman who, before and after sexual intercourse with that man, was examined by me and no signs of gonorrhea could be detected. Evidently the latent gonococci in the folds of the vagina, after being deposited in the male urethra, began to thrive on the new soil and set up the inflammation.

545 E. Water St.

\section{RECURRENT RHEUMATIC IRITIS.*}

RECOVERY, WITH A SEGMENT OF THE IRIS FIXED WITHOUT APPARENT SYNECHIA, WITH NORMAL ACUITY

OF VISION AND WITHOUT INCREASE OF MYOPIA, IN PATIENT WITH MYOPIC ASTIGMATISM.

BY S. D. RISLEY, A.M., M.D.

Attending Surgeon Wills Eye Hospital; Professor of Diseases of the Eye, Philadelphia Polyclinic and College for Graduates in Medicine. PHILADELPHIA, PA.

Mr. A., aged 35 years, with well-marked rheumatic diathesis, has for several years been subject to recurring iritis of a severe type. I have treated him through three violent and persistent attacks and several milder exacerbations of the disease. The last and most violent came on as a simple hyperemia of the iris, with impaired visual acuity on Oct. 22, 1898. A full dilatation of the pupil was immediately secured, when it was discovered that the fundus presented a uniform fluffy appearance and that there was a fine exudate in the anterior portion of the vitreous. Notwithstanding active treatment addressed to his diathesis and to the local conditions, the eye developed a violent and painful attack of iritis of the parenchymatous type, which confined him to his room until the close of November, and he did not resume his business until the middle of January. The in-

* Read before the College of Physicians of Philadelphia-Section on Ophthalmology. 